Madrygal. Revista de Estudios Gallegos

ISSN: $1138-9664$

\title{
La pobreza de los expósitos de la Inclusa de Pontevedra (1872-1925)
}

\author{
Ana María Rodríguez Martín ${ }^{1}$
}

Recibido: 27 de marzo de 2019 / Aceptado: 18 de xaneiro de 2020

Resumen. Este artículo tiene dos objetivos. El primero es establecer el medio del que procedían los expósitos de la Inclusa de Pontevedra y, ya de adultos, las circunstancias en las que se desenvolvían y morían. El segundo es valorar cómo eran vistos por la sociedad y cómo les afectaba tener la condición de hijos de padres desconocidos. Todo ello en el período que va desde 1872, año de la inauguración de la Institución, hasta 1925, cuando se cerró el torno. Para lograr los objetivos citados hemos analizado las ropas que estos niños vestían y las notas que portaban enganchadas a ellas al ser abandonados. Además, hemos establecido algunas características de la vida adulta de estos expósitos centrándonos en los bienes con los que contaban al comenzarla, el nivel de estudios que tenían y los trabajos a los que se dedicaban. También hemos estudiado la consideración social de los expósitos a través, sobre todo, de la prensa y de las manifestaciones de los responsables de las inclusas. Por último, hemos analizado testimonios de la búsqueda de algunos expósitos de información que pudiera llevarlos hasta su madre y su familia. Nuestras conclusiones son que, en buena parte, los expósitos de la Inclusa de Pontevedra, al igual que los asilados de otras inclusas, nacían pobres y morían de la misma manera, sin que la estancia en este establecimiento benéfico y, posteriormente, en el Hospicio les hubiera facilitado el ascenso social. Además, si no eran recogidos por su madre o familiares, no lograban encontrar a su familia biológica, y a esta carencia había que sumarle la poca consideración social que tenían los expósitos debido, precisamente, a ser hijos de padres desconocidos.

Palabras clave: Pobreza; expósitos; inclusas; Pontevedra; siglos XIX y XX.

\section{[gal] A pobreza dos expósitos da Inclusa de Pontevedra (1872-1925)}

Resumo. Este artigo ten dous obxectivos. O primeiro é establecer o medio do que procedían os expósitos da Inclusa de Pontevedra e, xa de adultos, as circunstancias nas que se desenvolvían e morrían. O segundo é valorar como eran vistos pola sociedade e como lles afectaba ter a condición de fillos de pais descoñecidos. Todo iso no período que vai desde 1872, ano da inauguración da Institución, ata 1925, cando se pechou o torno. Para lograr os obxectivos citados analizamos as roupas que estes nenos vestían e as notas que portaban enganchadas a elas ao seren abandonados. Ademais, establecemos algunhas características da vida adulta destes expósitos centrándonos nos bens cos que contaban ao comezala, o nivel de estudos que tiñan e os traballos que facían. Tamén estudamos a consideración social dos expósitos a través, sobre todo, da prensa e das manifestacións dos responsables das inclusas. Por último, analizamos testemuños da procura dalgúns expósitos de información que puidese levarlles ata a súa nai e a súa familia. As nosas conclusións son que, en boa parte, os expósitos da Inclusa de Pontevedra, do mesmo xeito que os asilados doutras inclusas, nacían pobres e morrían da mesma maneira. A estancia neste establecemento benéfico e, posteriormente, no Hospicio non lles facilitou o ascenso social. Ademais, se non eran recollidos pola súa nai ou familiares, non lograban atopar a súa familia biolóxica, e a esta carencia había que sumarlle a pouca consideración social que tiñan os expósitos debido, precisamente, a ser fillos de pais descoñecidos.

Palabras chave: Pobreza; expósitos; inclusas; Pontevedra; séculos XIX e XX.

\section{[en] The Poverty of the Foundlings of the Orphanage of Pontevedra (1872-1925)}

Abstract. This article has a double purpose. The first one is to establish the social enviroment the foundlings of the Inclusa de Pontevedra (the orphanage of Pontevedra) came from and once adults, the circumstancies in which they lived and died. The second aim is to analyze how foundlings were regarded by the society and how their condition of orphans affected them. This study starts with the opening of the institution in 1872 and reaches the end of the anonymous admissions in it in 1925. In order to achieve these aims the clothing and the notes attached to it when the children were abandonned have been

1 Doctora en Historia por la Universidad de Barcelona. Catedrática de Educación Secundaria.

Correo-e: anarmartin@yahoo.es; http://orcid.org/0000-0003-1799-0939. 
analized. Moreover, we have established some features of foundlings in their life as adults taking into consideration their means at birth, their educational levels and jobs they performed. Thorought press articles and the orphanage director's statements mainly, the social reputation of the foundlings has been also studied. Foundlings' attempts to find their mothers or relatives have been documented and analysed. We might conclude that foundlings of the Inclusa de Pontevedra as well as those from other institutions were born poor and remained poor until death. The orphanage or any other charity they stayed afterwards failed to improve their lifes' conditions. Children who were not picked up by their mothers who had left them behind did not have a biological family and because of that they were stigmatized as they were of unknown parents.

Keywords: Poverty; foundlings; orphanages; Pontevedra; 19th and 20th centuries.

Sumario. 1. Introducción. 2. El ingreso de los expósitos en las inclusas españolas en la segunda mitad del siglo XIX y primer tercio del XX. 2.1. El torno. 2.2. Las exposiciones fuera del torno. 3. La pobreza de los niños expósitos de la Inclusa de Pontevedra, 1872-1925. 3.1. Las prendas de ropa. 3.2. Las notas. 3.3. Los apellidos. 4. Los expósitos pontevedreses adultos de las generaciones de 1872-1925. 4.1. La pobreza. 4.2. Los problemas de identidad y la carencia de familia. 5. La consideración social de los expósitos en España. 6. Conclusiones. 7. Referencias bibliográficas.

Como citar: Rodríguez Martín, A. M. (2020): "La pobreza de los expósitos (1873-1925)", en Madrygal. Revista de Estudios Gallegos 23, pp. 295-313.

\section{Introducción}

El objetivo de este artículo es el análisis del medio en el que nacían y en el que se desenvolvían de adultos los expósitos de la Inclusa de Pontevedra ingresados entre los años 1872 y 1925. La Inclusa tenía categoría de establecimiento benéfico provincial, dependía de la Diputación, y acogía tanto a hijos legítimos como a ilegítimos y expósitos. Nosotros nos centraremos en estos últimos, que eran los niños recién nacidos o de poca edad, abandonados o expuestos, o bien confiados a un establecimiento de beneficencia ${ }^{2}$. Los expósitos podían ser, en origen, legítimos o ilegítimos, pero si habían sido echados al torno su filiación resultaba desconocida porque, precisamente, este artilugio garantizaba el anonimato en el abandono.
En la Inclusa de Pontevedra, la inmensa mayoría de los expósitos habían ingresado por el torno, por lo que se desconocía la identidad de sus padres. Nuestra hipótesis respecto a estos niños es que, mayoritariamente, procedían de las capas más pobres de la población y que de adultos seguían en ellas, sin que la Inclusa y el Hospicio, a donde iban tras cumplir los siete años, cambiasen esta situación.

Para realizar este trabajo hemos utilizado los libros de matrícula de la Inclusa y el Hospicio, los expedientes personales de los expósitos en ambas instituciones y la documentación generada por los órganos directivos de la Diputación. A través de las hemerotecas del Museo de Pontevedra y de Galiciana digital hemos analizado la información que sobre la Inclusa y sus asilados aparecía en la prensa de la ciudad. Por último, con textos de la época hemos visto la consideración social de los expósitos. En todo momento hemos comparado, utilizando bibliografía especializada, la situación de los expósitos pontevedreses con la de los ingresados en otras inclusas españolas y con la de los niños no asilados.

En la segunda mitad del siglo XIX muchas inclusas admitían solo a expósitos, sin embargo, en otras también entraban hijos legítimos, siempre que fueran huérfanos pobres, e ilegítimos procedentes de las maternidades. Conforme avanzaba el período que tenemos en cuenta, se fue imponiendo como criterio de ingreso el de desvalimiento y desamparo del menor, independientemente de si era o no ilegítimo (Diputación Provincial 1883: 44).

La Inclusa de Pontevedra empezó a funcionar el 1 de julio de $1872^{3}$. En un principio, su objetivo era acoger solo a expósitos, pero sabemos que ya en 1884 ingresaron niños legítimos huérfanos ${ }^{4}$, y a partir de esa fecha entraron menores con padres viudos, o madres enfermas, dementes, discapacitadas mentales o que no tenían leche ${ }^{5}$. Sin embargo, desde que se inauguró la Inclusa, y con ella el torno, el porcentaje de expósitos siempre fue altísimo, entre el $71,7 \%$ y el $94 \%$ de los ingresados (ADP, u.i. 14.721/2-14.730/3). Nosotros

Diccionario de la lengua española 2004: 1.023.

Archivo de la Diputación de Pontevedra (en adelante: ADP), unidad de instalación (en adelante: u.i.) 993.

Sesiones de la Comisión Provincial (a partir de ahora, CP), 7-6-1884, 19-6-1884 y 11-7-1884. ADP, u.i. 13.027, pp. 191, 207-208 y 219-220, respectivamente.

5 Sesiones de la CP, 5-2-1890, 7-9-1893, 26-9-1893, 13-2-1895 y 12-11-1895. ADP, u.i. 13.033, p. 46; 13.036, pp. 195 y 205 ; y 13.038 , pp. $58-59$ y 232 , respectivamente. 
vamos a centrarnos exclusivamente en este tipo de asilados, en un período de tiempo que abarca desde la inauguración de la Inclusa, en 1872, hasta el cierre del torno en 1925.

\section{El ingreso de los expósitos en las inclusas españolas en la segunda mitad del siglo XIX $\mathrm{y}$ primer tercio del siglo $\mathrm{XX}$}

Los expósitos podían entrar en las inclusas por el torno o por la puerta. En este último caso se trataba de niños que habían sido expuestos en algún lugar y eran remitidos por los alcaldes o las autoridades de esa zona, o bien eran entregados de forma anónima por una persona en el centro benéfico o bien procedían de una maternidad. La característica común a los expósitos era la imposibilidad de conocer y reunirse con su familia biológica, a no ser que sus madres o padres tomaran la decisión de recogerlo.

En las inclusas, los expósitos ingresados eran lactados por las amas internas y pasado un tiempo, que variaba de unos días a unas semanas, eran entregados a nodrizas externas, mayoritariamente rurales. Estas mujeres tenían que inscribir a los niños a su cargo en el padrón de pobres de sus ayuntamientos para que pudieran tener, en caso de necesitarlo, y de forma gratuita, servicio médico, medicinas y entierro. Vemos, pues, que desde el comienzo de su vida estos niños estaban en el grupo de los pobres (Diputación Provincial de Guipúzcoa 1916: s. p.).

Cuando los expósitos cumplían cinco o siete años, edad que variaba según las inclusas, las amas ya no cobraban por ellos. Sin embargo, algunas se los quedaban y otras, por contra, los devolvían al establecimiento benéfico de donde procedían. De allí, generalmente, eran trasladados a un hospicio en el que permanecían hasta que salían para hacer vida independiente.

\subsection{El torno}

Un porcentaje apreciable de los niños que ingresaban en las inclusas españolas era entregado personalmente, ya fuera por la madre, un familiar, la partera e, incluso, alguna mujer que ocasional o regularmente transportaba recién nacidos de los pueblos a las inclusas ${ }^{6}$. También, desde finales del siglo XIX, cada año ingresaban más niños procedentes de las maternidades, instituciones que permitían a las mujeres, en su inmensa mayoría solteras, parir secretamente y de la misma manera dejar a sus hijos en las inclusas. Sin embargo, una gran proporción de los niños entraban por el torno. Este artilugio, de uso generalizado en Europa en el siglo XIX, fue objeto de debate sobre su conveniencia y sobre las consecuencias de su supresión. Los defensores del torno alegaban que el anonimato total que garantizaba permitía reducir los infanticidios y las exposiciones salvajes, es decir, el abandono de los niños a la intemperie, que tenían como resultado, en muchos casos, la muerte. El director de la Casa de Maternidad y Expósitos de Barcelona, en 1878 , era de esta opinión y afirmaba que si no se respetaba el secreto en la entrega del niño, las consecuencias serían nefastas,

(...) ha cundido algún día la falsa voz de que en aquel asilo se hacía preguntas a los que entraban expósitos; y en aquellos días, era escandaloso el número de criaturas que se encontraban por las calles moribundas o muertas por el frío y por el hambre, y aún se dio el caso de encontrarse alguna destrozada por los perros. (Roure 1878: 15)

Según este director, los abandonos de este tipo disminuyeron después de que afirmara públicamente que se garantizaba el anonimato de los que allí depositaban a sus hijos. Un periódico, ya en 1920, también apuntaba como causa de que un recién nacido fuera abandonado en la catedral de Ourense a que el torno, y el secreto que conllevaba, había sido suprimido unos días antes ${ }^{7}$.

En contra de la existencia del torno se presentaban argumentos diversos: que favorecía el desorden sexual y los abandonos, y que facilitaba que mujeres desaprensivas se deshicieran de sus hijos y se colocasen luego como nodrizas, provocando el aumento del número de niños alimentados a costa de fondos públicos (Blanco Herrero 1869: 58-62; Juderías 1912: 58-59). Concepción Arenal creía que las mujeres, al considerar el torno como una opción, dejaban de lado sus deberes de madre y hacían aumentar el porcentaje de niños abandonados. Opinaba, además, que no estaba

\footnotetext{
6 “Pobre y con hijos", El Progreso (Pontevedra) 6/2/1919, http://biblioteca.galiciana.gal.

“Apuntes noticieros", El Diario de Pontevedra (Pontevedra) 21/1/1920, http://biblioteca.galiciana.gal.
} 
completamente demostrada la teoría que sostenía que la desaparición de los tornos acrecentaba la cantidad de infanticidios y de recién nacidos que morían (Arenal 1878: 91). Ya en la segunda década del siglo XX, algunos médicos de la Inclusa de Madrid señalaban que el cierre del torno permitiría obtener los antecedentes patológicos de los ingresados y evitaría el abandono de muchos niños legítimos (Espina Pérez 2005: 355). En esa línea, la Sociedad de Pediatría de Madrid pidió su supresión en $1919^{8}$.

En Europa, en el siglo XIX, también hubo debates sobre la conveniencia de los tornos (Bardet 1991: 17-19). La postura que se impuso fue la favorable a su cierre, que se tradujo en la clausura de estos artilugios a lo largo de los dos últimos tercios del siglo XIX ${ }^{9}$ (Langellotti y Travaglini 1991: 750; Lopes 2004: 50-51). Por contra, en España aún seguían abiertos a comienzos del siglo siguiente, aunque se fueron suprimiendo paulatinamente hasta que llegó la II República. En este período se cerraron los que aún quedaban operativos, que eran, mayoritariamente, los que solo abrían por la noche (Valverde Lamsfus 1994: 82-83). Esto sucedió cuando ya el porcentaje de ingresados por los tornos era pequeño, dado que había ido bajando desde finales del siglo XIX porque cada vez entraban más niños procedentes de las maternidades (Montiel i Pastor 2004: 58 y 83).

En Galicia, en la tercera década del siglo XX, se cerraron los tornos de Ourense, Lugo y Mondoñedo ${ }^{10}$ y en 9-5-1925 el de Pontevedra, en principio provisionalmente, pero luego de forma definitiva ${ }^{11}$. La razón alegada por la Diputación pontevedresa para su supresión era la falta de nodrizas externas que provocaba la saturación en los locales de la Inclusa y, por consiguiente, una mayor mortalidad. Sin embargo, este organismo provincial aclaraba que se seguirían admitiendo niños desvalidos pobres, pero ya debidamente identificados y en número limitado, “(...) no se impedirá el ingreso por la puerta, en casos urgentes de pobreza comprobable y con la reserva obligada, siempre que la capacidad de los locales lo permita"12.

\subsection{Las exposiciones fuera del torno}

Las exposiciones, es decir, los abandonos de recién nacidos a la puerta de una iglesia, o de una casa, o en un lugar público ${ }^{13}$ se producían en España tanto en las ciudades, incluso las que contaban con algún torno, como en las zonas rurales. Estas exposiciones se hacían, sobre todo, por la noche y en lugares en los que, en cuanto amaneciera, sería fácil encontrar al menor (Sánchez Fernández, Cobo Barquín et al. 2013: 157). En Galicia, se trataba de atrios de iglesias, caminos, puertas o portales de casas, y la vía pública ${ }^{14}$. El Código Penal de 1848 y su reforma de 1870 castigaban con arresto mayor y multa a los que hubieran abandonado a un menor de siete años, pero si las circunstancias de esta exposición hubieran puesto en peligro la vida del niño, la pena era de prisión correccional (Serrano Ruiz-Calderón 2003: 38-41). Por ese temor al castigo, un periódico de Ourense explicaba que una mujer, que había sido sorprendida y detenida tras haber dejado a su hijo en el claustro de un convento, negaba el abandono,

(...) declaró (la mujer) que efectivamente era hija suya la recién nacida, que no tenía con que poder atender á la subsistencia del fruto de sus entrañas y que no había pensado en abandonarlo. Por el contrario llevaba la criatura á la puerta de la iglesia para ver si una persona caritativa llegaba y la recogía aunque después la condujesen á la inclusa ${ }^{15}$.

8 "La Sociedad de Pediatría pide la supresión del torno en las inclusas", El Progreso (Pontevedra) 23/12/1919, http:// biblioteca.galiciana.gal.

9 En la actualidad, en algunos países europeos, como Alemania y Austria, se han instalados tornos, más modernos y con otra denominación, pero con iguales finalidades declaradas: el abandono anónimo del hijo y la salvación de la vida del niño. "Buzones para salvar bebés. Viena instala en la calle un aparato que permite a cualquier madre abandonar sin riesgos a su hijo", El País (Madrid) 3/11/2000.

10 “Apuntes noticieros", El Diario de Pontevedra (Pontevedra) 5/1/1920. "Noticias", El Progreso (Pontevedra) 11/11/1928, http://biblioteca.galiciana.gal.

11 Sesión de la CP, 16-5-1925. ADP, u.i. 13.150, p. 9.

12 "El cierre de la Inclusa", El Diario de Pontevedra (Pontevedra) 8/5/1925, http://biblioteca.galiciana.gal.

13 Diccionario de la lengua española 2004: 1.022.

14 "Noticias de Galicia”, La Correspondencia gallega (Pontevedra) 27/4/1897 y 23/5/1898. “Apuntes noticieros", El Diario de Pontevedra (Pontevedra) 27/4/1897, http://biblioteca.galiciana.gal.

15 “Desde Santiago", El Áncora (Pontevedra) 25/1/1901. 
Seguramente algunas exposiciones en la provincia de Pontevedra tuvieron como final la muerte del niño por frío, desnutrición o por ataques de animales, pero solo tenemos en cuenta las que terminaban en la Inclusa. Estas exposiciones, que se producían tanto en comarcas alejadas del torno de este establecimiento benéfico como en la capital ${ }^{16}$, fueron disminuyendo a lo largo del período que consideramos. Si en 1873 el 50,98\% de los ingresados ese año habían sido expuestos fuera del torno, creemos que porque apenas se conocía la existencia de la recién creada Inclusa, en 1883 el porcentaje había bajado al 3,08\% (Rodríguez Martín 2001: 75), y a partir de 1906 fluctuó entre el $3,40 \%$ y el $0,54 \%$ (ADP, u.i. $14.725 / 3-14.730 / 3)$.

\section{La pobreza de los niños expósitos de la Inclusa de Pontevedra, 1872-1925}

Todos los niños que ingresaban en la Inclusa de Pontevedra eran anotados en un libro de registro en el que se consignaba día, hora y modalidad de ingreso, y sus características personales especiales, ya fuera un lunar, la ceguera, alguna fractura o discapacidad. Además, para facilitar la identificación de los menores que entraban se detallaban sus prendas de ropa y, si llevaban consigo una nota, su contenido, como ocurría en otras inclusas (Seijo Castro 2015: 172). Estas anotaciones dejaron de hacerse a partir de 1925, cuando se cerró el torno y los niños que ingresaban lo hacían tras la apertura de un expediente, es decir, totalmente identificados ${ }^{17}$.

\subsection{Las prendas de ropa}

En la Inclusa de Pontevedra, durante los años que funcionó el torno, los ingresados que iban vestidos con prendas nuevas y de mediana calidad eran una excepción porque la mayoría llevaban pocas ropas, viejas y remendadas, calificadas muchas veces en el libro de registro como trapos. Incluso, algunos de ellos fueron depositados desnudos en el torno, y otros cubiertos solo con un trozo de tela, manta o toalla, o con una funda de almohada. Una nota que llevaba encima un recién nacido ingresado en 1909 explicaba la situación, "Por no tener otra cosa, lleva por toda indumentaria una saya y un mantón verde" (ADP, u.i. 14.726/2). Sin embargo, se observa una mejoría: si en 1906 el $87,8 \%$ de los niños entraba en la Inclusa con prendas anotadas como trapos, en 1918 solo lo hacía el $69,9 \%{ }^{18}$. El mal estado y la escasez de las ropas que portaban estos expósitos, circunstancia común con otras inclusas (Díez 1992: 457; Salas 2006: 164), nos indica la pobreza de sus madres y del medio del que procedían.

\subsection{Las notas}

Muchos niños en la Inclusa de Pontevedra, al igual que en otros centros benéficos similares españoles y europeos (Fonte, 2005: 336-337; Barba 2017: 280), eran abandonados con una nota o trozo de papel, generalmente basto, en el que estaba escrito un número variable de datos, como la fecha de la exposición y/o del nacimiento, la descripción de las ropas, objetos y señales que portaba, características personales, aclaración de si había recibido o no el bautismo, solicitud del nombre e, incluso, apellidos que se impondrían y causas del abandono. Nosotros nos centraremos en las notas que llevaban los niños ingresados ya en el siglo XX. Veamos un ejemplo de nota ${ }^{19}$,

Vigo (...) de 1909 Con esta misma fecha ha nacido un niño á la una de la mañana; y por falta de recursos me obliga la necesidad á pedirle a ésa santa casa de caridad y el favor de asistirme este hijo; que con mucho dolor de corazón lo separo de mi lado; va sin bautizar, le agradeceré lo bauticen cuanto mas hantes posible, poniéndole el nombre de XX lleva una medalla de metal con el sagrado corazón de Jesus por un lado, y por el otro Maria Auxiliadora; que con la ayuda de Dios, dentro de algunos años piensa sacarlo (ADP, u.i. 14.726/2).

Las notas no solían llevar firma y estaban escritas con letra insegura y con numerosas faltas de ortografía, “(...) entra oy Por Poco tiempo mediante Dios que es por enfermedad de su Madre y si Dios quier que se Ponga Buena

\footnotetext{
16 ADP, u.i. 993, 977 y $14.721 / 2$ al $14.731 / 2$.

17 Las exposiciones tras el cierre del torno fueron poquísimas. De ellas se encargaba el juez de la zona y luego la Comisión Provincial autorizaba el ingreso del menor. ADP, u.i. 14.730/3 y 14.731/1-2.

18 ADP, u.i. $14.725 / 3,14.726 / 1$ y $14.729 / 1$.

19 Se ha respetado la ortografía original de las notas.
} 
se Reclamara y el Padre Pide a todas Vdes miren Por el que Dios se lo Pajara" (ADP, u.i. 14.729/3). Muchas de estas notas reflejaban la poca instrucción de las madres ${ }^{20}$. Debemos tener en cuenta que, en 1887, en Galicia, el analfabetismo afectaba al $72,63 \%$ de la población, pero si consideramos solo a las mujeres, ascendía al 89,35\% (Castro 2007: 174). La Ley de 23-6-1909 que estableció la escolarización obligatoria hasta los 12 años provocó un descenso pronunciado del analfabetismo femenino, pero el porcentaje siguió siendo importante, tanto en Galicia como en toda España, en donde llegaba al 47,5\% de las mujeres y al 36,0\% de los hombres en 1930 (Capel Martínez 1982:145, Benso Calvo y Cid Galante 2011: 48-50).

Las notas solían tener tono suplicante a pesar de que la Diputación pontevedresa, de acuerdo con la ley del 21-10-1903 sobre vagancia y mendicidad de los menores de 16 años, tenía que hacerse cargo de los huérfanos, de los niños abandonados o de aquellos que no podían ser cuidados por sus padres por falta de medios (Consejo Superior de Protección a la Infancia 1908: 56). En algunas de las notas no se detallaban las causas del abandono, “... no la puede criar su madre por grandes acontecimientos y muchas necesidades" (ADP, u.i. $14.725 / 3$ ), pero lo más corriente es que sí se explicaran. La ilegitimidad no era citada, y apenas se hablaba de problemas familiares, “(...) Por razones de familia no la puedo criar" (ADP, u.i. 14.725/3). Sin embargo, se insistía en la pobreza, al igual que en las notas de otras inclusas (Revuelta Eugercios 2011: 283), “(...) y que por carecer su madre de recursos por ser pobre de solemnidad lo deposita afin de recojerlo tan pronto como pueda" (ADP, u.i. 14.726/3). Esta pobreza solía ir unida a otra circunstancia negativa, como la falta de leche de la madre, "(...) por allarse su madre gravemente enferma sintener recursos para alimentarlo", o bien su enfermedad “(...) esta la madre muygrabe y tiene 6 hijos y espobre de solenidad", o su locura, "(...) la enfermedad que padece su madre es demencia" (ADP, u.i. $14.725 / 3,14.727 / 2$ y 14.729/3). En otras ocasiones era la muerte de algún progenitor, “(...) no tiene Madre que falleció y no tiene alimentos", "huérfana de padre y madre sin recursos", agravada si había varios hermanos (ADP, u.i. 14.725/3, 14.730/2 y 14.728/2). Según algunas notas, la necesidad imperiosa de trabajar de madres pobres y solas provocaba el depósito del niño en el torno, “(...) tiene solo madre, no necesita ama pues ya está en disposición de comer, y su madre lo deposita en el Torno (...), por carecer de recursos para sus necesidades puesto que tiene que trabajar para ganar su sustento, y el niño se lo impide" (ADP, u.i. 14.726/2). Estas notas son un reflejo del umbral de la pobreza en la que vivía gran parte de la población, a la que cualquier circunstancia negativa abocaba a la pobreza total (Ballesteros Doncel 1999: 573-586). En esa situación era muy difícil criar a un hijo, máxime para las mujeres trabajadoras que, además de cobrar menos que un hombre, no contaban con el salario de un marido por ser solteras o haber sido abandonadas (San Martín 1985: 158).

El miedo que había en la sociedad hacia la sífilis, provocaba que en algunas notas se asegurase la limpieza de la madre y del hijo, “(...) Su madre no padece ninguna enfermedad contagiosa" (ADP, u.i. 14.728/2), y que el menor era fruto de legítimo y honrado matrimonio, "(...) le pido a V. de favor que lo estimen como igo de guente onrada y de vuena sangre", "es hijo de matrimonio se echa por la necesida de que murió su padre y le queda 7 hijos" (ADP, u.i. 984 y 14.727/2). Sin embargo, otras notas declaraban la enfermedad del niño, de la madre, “(...) al cual no le puede dar la madre el pecho por estar sifilítica", o del padre, "esta niña es hija de sifilitico aunque estava en tratamiento" (ADP, u.i. 14.727/2 y 14.726/3).

Muchas notas expresaban la intención de la progenitora o de los familiares de recoger al menor, "Su madre ha fallecido. A su tiempo será recogido por sus abuelos" (ADP, u.i. 14.726/3). Que la promesa se cumpliera se hacía depender, algunas veces, de que mejorara la situación económica, “(...) por estar su madre faltosa de recursos y la recogerá cuando mejoré de fortuna", o la salud materna, "(...) en cuanto su madre se ponga restablecida", o del regreso del padre del niño, “(...) se recojera lo mas pronto posible, tan pronto llegue su padre de Africa que esta pronto a llegar", o

20 Algunas notas podrían no haber sido escritas por las madres, sino por alguien con la alfabetización suficiente para redactar unas cuantas frases. Podría tratarse de los abuelos u otros parientes del niño abandonado, o bien de alguna persona cercana a la familia. 
de que la criatura no necesitase mamar (ADP, u.i. $14.726 / 2$, $14.727 / 2$ y 14.730/2). Pocas promesas de recuperación del hijo que se abandonaba se hicieron realidad. Si nos fijamos en la tabla $\mathrm{n}^{\mathrm{o}} 1$, veremos que solo un $1,33 \%$ fue recogido por sus progenitores o familiares debido, quizás, a la pobreza, la falta de salud de la madre, el fallecimiento de uno o los dos progenitores, o a cualquier otra causa, incluida la de no desear volver atrás en el abandono. También debemos considerar que muchos niños no pudieron ser recogidos porque habían muerto.

\begin{tabular}{l|c|c}
\multicolumn{1}{c|}{ Niños } & número & $\begin{array}{c}\text { \% sobre los } \\
\text { ingresados }\end{array}$ \\
\hline Ingresados & 1.660 & \\
\hline Con nota & 843 & $50,78 \%$ \\
\hline $\begin{array}{l}\text { Con nota con promesa de } \\
\text { recogida }\end{array}$ & 451 & $27,17 \%$ \\
\hline $\begin{array}{l}\text { Con nota con promesa de } \\
\text { recogida cumplida }\end{array}$ & 6 & $0,36 \%$ \\
\hline
\end{tabular}

Tabla 1. Número y porcentaje de ingresados en la Inclusa de Pontevedra con notas de promesa de recogida, y niños recuperados efectivamente, 1873-1924 ${ }^{21}$

Si comparamos las notas escritas ya en el siglo $\mathrm{XX}$ con las del siglo anterior, vemos que sus características variaron poco. En todas ellas abundaban las promesas de recuperación, que se hicieron realidad en poquísimos casos, y la causa del abandono que más se citaba era la pobreza (Rodríguez Martín 2001: 76-79).

\section{3. Los apellidos}

La mayoría de los expósitos eran hijos de padres desconocidos, por lo tanto, no tenían apellidos. Esta circunstancia los colocaba en el puesto más bajo del grupo de pobres. Para corregir esta situación, la ley del Registro Civil de 1870 estableció que, para que nada delatara su condición, los encargados de los registros civiles tenían que imponerles un nombre y un apellido que debían ser usuales. Si el niño al ser abandonado llevaba una nota en la que se indicaba el apellido que se quería que se le asignara, los registros civiles cumplían este deseo, como estaba previsto legalmente ${ }^{22}$.

La mayoría de los ingresados en la Inclusa de Pontevedra recibieron un apellido del grupo de los más corrientes en Galicia ${ }^{23}$ y solo a muy pocos expósitos se les puso los típicamente incluseros, Rey o Iglesias. A otros, no muchos, los inscribieron con el apellido Pontevedra, o le pusieron el de la calle en la que fueron abandonados y encontrados. En otros casos, se trataba de apellidos no usuales, referidos a ríos, playas y personajes míticos relacionados con Pontevedra (ADP, u.i. 14.721/2-14.725/1). Esta falta de sensibilidad de algunos de los encargados de los registros civiles no era excepcional. Algunos expósitos de las inclusas de Pamplona y Barcelona recibieron apellidos que incitaban a la burla (Valverde Lamsfus 1994: 221; Rodríguez Martín 2005: 181-182).

Aunque los expósitos solo tenían un apellido, la prensa y también el ayuntamiento de Pontevedra cuando los reclamaba para el cumplimiento del servicio militar, les añadían el de Expósito ${ }^{24}$. Para evitarlo, la Real Orden del 11-4-1903 estableció que se les pusieran dos apellidos para borrar su condición, "de modo que no revele ni indique la circunstancia de su filiación ilegítima" (Abella Blave 1903: 347). Sin embargo, en ocasiones, el Registro Civil de Pontevedra no respetó el espíritu de esta Real Orden y algún expósito recibió los apellidos de dos de los políticos más destacados de la Restauración, o bien una combinación con los nombres de la región, Galicia, y de ciudades y ríos pontevedreses ${ }^{25}$. A partir 1914 ya no encontramos casos de este tipo, aunque a algunos niños se les pusieron apellidos tradicionalmente incluseros, como el de Expósito, o bien catalanes o vascos, sin que conozcamos el criterio seguido por el encargado del Registro Civil de Pontevedra ${ }^{26}$.

21 Fuentes: elaboración propia a partir de los libros de matricula de la Inclusa de Pontevedra. ADP, u.i. 14.721/2 al 14.730/3. Hemos considerado las generaciones de los años 1873, 1878, 1883, 1888, 1893, 1898, 1903, 1906, 1909, 1912, 1915, 1918, 1921 у 1924.

22 Reglamento de fecha 13-12-1870 para la ejecución de la Ley de Registro Civil, art. 34. Abella Blave 1903: $141-142$.

23 No en todos los libros de registro de entrada de la Inclusa de 1873-1903 consta el apellido impuesto a los expósitos.

24 ADP, u.i. 962 y 977. "Los fugados de Carballo", La Correspondencia Gallega (Pontevedra) 22/4/1903. "Crimen en Villagarcía”, Diario de Pontevedra (Pontevedra) 4/5/1911. "Del Municipio”, El Progreso (Pontevedra) 29/1/1919, http://biblioteca.galiciana.gal.

25 ADP, ui. 14.725/3-14.726/1, 14.726/3 y 14.727/2. "Comisión provincial”, La Correspondencia gallega (Pontevedra) 26/6/1906, http://biblioteca.galiciana.gal.

26 ADP, u.i. 14.729/3. "Los recogidos en la Inclusa", El Progreso (Pontevedra) 14/2/1914, http://biblioteca.galiciana.gal. 


\section{Los expósitos pontevedreses adultos de las generaciones de 1872-1925}

Una vez que cumplían los siete años, los expósitos de la Inclusa de Pontevedra podían quedarse con sus amas externas, si éstas así lo querían. En caso contrario, regresaban a la Institución y de allí eran trasladados al Hospicio, en donde permanecían hasta que salían para trabajar y hacer vida independiente. En este apartado trataremos de ver si, ya de adultos, los expósitos de la Inclusa de Pontevedra lograron escapar de la pobreza, y para ello tendremos en cuenta los oficios que desempeñaron y su nivel de estudios. Consideraremos dos etapas. La primera abarca desde la fundación de la Institución, en 1872, hasta el año 1904, cuando se publicó la Ley de Protección a la Infancia que establecía la protección y la vigilancia de la salud física y moral de los niños de menos de 10 años por parte de los poderes públicos. En el grupo de estos menores estaban comprendidos los entregados a la lactancia mercenaria o los que estuvieran en casas-cuna, escuelas, talleres y asilos (Consejo Superior de Protección a la Infancia 1908: 15). La segunda etapa comprende desde 1905 hasta el año en el que se cierra el torno, 1925.

\subsection{La pobreza}

\subsubsection{Generaciones de 1872-1904}

La Inclusa de Pontevedra tenía pocas noticias de los niños mayores de 7 años que se habían quedado con su nodriza. La tutela de la Institución, que ya sobre los menores de esta edad presentaba muchos fallos, a partir de los siete años era prácticamente inexistente, como ocurría en otras inclusas (Valverde Lamsfus 1994: 272-274). En la de Pontevedra, en los expedientes personales de los asilados muchas veces solo encontramos una petición del interesado de su partida de bautismo y, sobre todo, de la de nacimiento, necesarias para casarse o pedir su jubilación. En este último caso, algunos la solicitaban en impreso de pobreza. Con los pocos datos con los que contamos podemos concluir que una parte importante de los expósitos adultos se dedicaban a trabajos manuales y humildes, como jornalero o cantero. En otras inclusas se dedicaban a oficios parecidos. Eran criados, jornaleros y, muy pocos, artesanos (Salas 2006: 181).
De algunos expósitos de la Inclusa de Pontevedra, ya adultos, sabemos que tuvieron problemas con la justicia, pues estuvieron incursos en procesos judiciales, la mayoría por hurto o robo (ADP, u.i. 943, 962, 980 y 984). Varios antiguos asilados, en su vejez, al ser pobres y no tener familiares, ingresaron en diversas instituciones, corriendo con los gastos la Diputación $^{27}$. De otros sabemos que emigraron a América, pues desde allí, sobre todo desde Argentina, solicitaban su partida de nacimiento para la jubilación (ADP, u.i. 943).

De los expósitos de los que tenemos más información es de los que ingresaron en el Hospicio de Pontevedra por no querer sus nodrizas quedarse con ellos después de los siete años, dado que no cobraban por cuidarlos a partir de esa edad. La mayoría de los expósitos varones salió de esta Institución para comenzar a trabajar, generalmente, de zapatero, carpintero, sastre o músico, profesiones aprendidas en el Hospicio, en su banda de música y en sus talleres o en los de la capital. En 1906 había 25 jóvenes aprendices en los talleres externos, con edades comprendidas entre los $12 \mathrm{y}$ 17 años. En 1913, el número se había reducido a 16 (ADP, u.i. 924). Del salario que cobraban, el Hospicio se quedaba una cuarta parte y, además, les descontaba el importe de alguna compra que efectuaban, como la de un traje, unos zapatos o unas medias suelas. El resto del salario la Institución lo ingresaba en una libreta de ahorros para cuando estos asilados se marcharan para hacer vida independiente. El dinero que habían logrado reunir no solía ser mucho. Por ejemplo, I. R., que estuvo con un maestro relojero durante cinco años y cinco meses, de 1906 a 1912, tenía 137 pesetas (ADP, u.i. 924). Las que salían del Hospicio sin ningún dinero ahorrado eran las chicas, que se colocaban, mayoritariamente, de sirvientas, trabajo que habían aprendido y practicado en la Institución (Rodríguez Martín 2015: 144-157).

Todos los expósitos menores de 14 años iban a la escuela en el mismo Hospicio. Su nivel de estudios y los oficios que de adultos desempeñaron eran similares a los de los acogidos en otros hospicios españoles (Codina Langlín 1892: 100-101), con la diferencia de que en algunos de ellos varios varones llegaron a estudiar para maestros e, incluso, a finales del siglo XIX, alguna joven entró en una Escuela

27 Sesiones de la CP, 13-11-1925 y 30-6-1930. ADP, u.i. 13.150, p. 75 y 13.156, p. 70, respectivamente. 
Normal (Román Portas 1989: 53; Acosta Sánchez 1995: 329-356). El nivel de instrucción de los hospicianos pontevedreses no era muy elevado, pero iban a la escuela, algo que no ocurría en un porcentaje muy alto entre los niños no asilados. En las poblaciones costeras, en 1870, había una tasa de escolarización muy baja, como en Bueu, que tenía, para los menores de 11 años, solo un 29,85\% para los varones y 23,38\% para las niñas (Muñoz Abeledo 2013: 129). Además, debemos tener en cuenta que, en toda Galicia, en 1887, solo cursaban la segunda enseñanza 1.324 alumnos y, en 1889, solo 650 jóvenes estudiaban en las Normales para ejercer de maestros (Castro 2007: 177). Las mujeres solo eran el 2,5\% de los alumnos de bachillerato (Brey 2005:193)

Algunos expósitos duraron poco en el Hospicio. Se trataba de varones que al llegar a la adolescencia se fugaban. La mayoría eran localizados y trasladados de nuevo a la Institución, y de otros nunca más se supo. Otros expósitos, aunque muy pocos, permanecieron gran parte o toda su vida en el Hospicio, y algunos fueron trasladados de allí al manicomio de Conxo o al Asilo de Ancianos ${ }^{28}$. Se trataba de asilados con discapacidades intelectuales o físicas que les obligaron a depender siempre de la beneficencia. También acabaron en el Asilo de Ancianos algunos expósitos que viejos, enfermos y sin familia, no tenían a nadie que los cuidara. Todos estos mismos casos los vemos también en ingresados en otras inclusas (Espina Pérez 2005: 497; Seijo Castro 2015: 100 y 208).

Respecto a los expósitos que se habían quedado con su nodriza a partir de los siete años, que solía ser una cuarta parte de los entregados a estas mujeres (ADP, u.i. 14.725/3$14.730 / 3$ ), debieron empezar a trabajar ya de bien pequeños. Eran una mano de obra dócil y gratuita. Algunos, en su juventud, supusieron erróneamente que tenían derecho a heredar de su nodriza o de su esposo y por esa razón, ya de adultos, solicitaron información a la Inclusa (ADP, u.i. 974 y 14.723/2). La realidad es que solo en pocas ocasiones, y siempre de forma voluntaria, eran declarados herederos o recibían una casa o tierras en el testamento de sus antiguas amas de leche. Debemos tener en cuenta que estas mujeres eran, generalmente, pobres y que habían aceptado lactar a un expósito por un salario bajísimo, por lo que no tenían muchos bienes (Rodríguez Martín 2003:186). La incorporación al trabajo de los expósitos a cargo de sus nodrizas, a edades muy tempranas, antes de los diez años y tanto en las fábricas como en el campo y la pesca, sucedía también con los tutelados por otras inclusas españolas (Rodríguez Martín 2005: 307-308). En general, el trabajo infantil era frecuente y no fue hasta el 24-7-1873 que se publicó la primera ley que lo prohibió a los menores de diez años. También estableció una jornada de 5 horas para los niños menores de 13 años y para las niñas menores de 14 , y de 8 horas, como máximo, para los varones entre 13-15 años y para las chicas entre 14-16 (Soto Carmona 1989: 700). No obstante, el trabajo infantil siguió existiendo porque esta ley fue incumplida. En la industria, el trabajo de los niños era ventajoso económicamente para el patrono y los hogares pobres necesitaban el jornal de los hijos. Además, la ayuda de los menores era crucial para las familias campesinas y marineras que, incluso, llegaban a considerarla formativa (López Keller 1990: 151).

\subsubsection{Generaciones de 1905-1925}

De los expósitos que en la Inclusa o en el Hospicio fueron recogidos por sus familiares o por personas particulares tenemos poca información, lo mismo que de los poquísimos que fueron prohijados. De los niños que se quedaban después de los siete años con las nodrizas que los habían criado, que solían ser mujeres pobres, creemos que no tenían un gran futuro puesto que no cobraban por el trabajo que realizaban ya desde pequeños, al igual que los niños de las familias pobres (Castro 2008: 6673). La ley de 13-3-1900, vigente hasta 1934, prohibía el trabajo a los menores de diez años y establecía para los que tenían entre 10 y 14 años seis horas de trabajo diarias en la industria y 8 en el comercio, pero no regulaba el trabajo infantil en la agricultura $\mathrm{y}$, además, hasta la tercera década del siglo XX esta ley fue incumplida de forma generalizada (Borrás Llop 1996: 233-253; Ramas Varo 2001: 173181). Algunas nodrizas, ellas solas o junto a sus maridos, en compensación por la labor que realizaban los expósitos a su cargo, les nombraron herederos universales o les legaron una pequeña cantidad de dinero o fincas rústicas (ADP, u.i. 962). En otras ocasiones, no había retribución alguna a estos niños y jóvenes por 
su trabajo. Uno de ellos, ya adulto, en 1945, preguntaba al Administrador de la Inclusa si tenía derecho a cobrar algo. En su carta se deja ver el desarraigo y la falta de autoestima,

(...) mientras que cobraron por mi me tenian [las dos nodrizas consecutivas que tuvo] hecho un esclavo guardando ganado en el campo descalzo escuela ya be Vd. Lo bien que escribo y lo poco que se lo aprendi por el mundo adelante pues no era porque no tengan capital pues tienen bastante y eso es todo lo que adelante y si se un oficio porque acuenta de mis costilla lo aprendi pues mas baliera que me dejasen estar en el Hospicio por lo menos seria hoy algo y asi no soy nada. hasta la edad 17 años me tire con ellas trabajando pues yo creo que algo me merezco y Vd. Me puede informar si puedo reclamar algo o no $(\ldots)^{29}$.

Esta situación cambió en 1925 porque la Diputación Provincial estableció una serie de condiciones para toda persona que quisiera quedarse un hospiciano. Una de ellas es que tenía que ingresarle en su libreta postal una determinada cantidad anual ${ }^{30}$. Se trataba de que los expósitos comenzaran su vida adulta con algo de dinero. En esta línea, a partir de 1925, la Caja de Ahorros y la Comisión Provincial regalaron algunas libretas de ahorro, con 25 pesetas cada una, para sortear entre los expósitos existentes ${ }^{31}$. Como hecho excepcional hubo una donación importante, que fue la de una mujer que legó a la niña que llevara más tiempo en la Inclusa una casa ${ }^{32}$.

De los expósitos que ingresaron y permanecieron en el Hospicio hasta que salieron a trabajar tenemos algo más de información, aunque los libros de registro de entrada consignan pocos datos y los expedientes personales que se conservan son pocos, 9 de los 107 que tendría que haber ${ }^{33}$. De la consulta de todo este material podemos afirmar que las salidas del Hospicio eran voluntarias, entre los $17 \mathrm{y}$ los 19 años, y tenían carácter definitivo, salvo casos excepcionales ${ }^{34}$, y así se hacía constar claramente en los libros de matrícula de la Institución. Los trabajos que realizaban los hospicianos una vez emancipados eran, como en la etapa anterior, los de zapatero, impresor, cantero, jornalero, electricista o sirviente (ADP, u.i. 982 y 962). Muchos contaban con algo de dinero al salir del Hospicio porque habían trabajado ya antes ${ }^{35}$ y porque, como ya hemos visto, la Diputación en 1925 había establecido que los que tuvieran hospicianos y utilizaran sus servicios debían ingresarles unas cuotas anuales en sus libretas de ahorros ${ }^{36}$.

A partir de la generación de 1912 vemos un cambio en las ocupaciones de los expósitos, pues algunos salían del Hospicio para ser marineros, soldados, trabajadores en los talleres de la aviación o músicos en las bandas de los regimientos. Varios expósitos varones, de entre 15 y 18 años, durante la Guerra Civil y la postguerra, se marcharon del Hospicio a la casa de su antigua nodriza. De otros hospicianos no sabemos prácticamente nada porque en el libro de matrícula solo aparece la frase "salió voluntariamente" (ADP, u.i. 14.740 y 14.741/1-2).

Respecto a las hospicianas expósitas, algunas fueron recogidas a los siete $\mathrm{u}$ ocho años de edad por matrimonios o mujeres solas que aceptaban pagar las cantidades señaladas por la Diputación en 1925, y otras salieron del Hospicio en torno a los 20 años para trabajar de criadas (ADP, u.i. 14.740 y 14.741/1-2). En otros centros benéficos similares también había entre los asilados una diferencia según el sexo en la formación que recibían y que luego

29 Carta del expósito 4.346/15 al Administrador de la Inclusa, 20-1-1945. ADP, 962.

30 Anualmente se pagaría: de los 7 a los 10 años, 35 pts.; de 10 a 13 años, 60 pts.; de 13 a 16,90 pts.; de 16 a 20,140 pts., y, por último, de 20 a 23 años, 180 pts. ADP, u.i. 933.

31 Sesiones de la CP, 6-11-1925 y 4-11-1927. ADP, u.i. 13.150, p. 73 y 13.153, p. 34, respectivamente.

32 Efectivamente, en 1926, siendo la expósita ya una joven, recibió 16.225 pesetas de la venta del inmueble. ADP, u.i. 14.741/1-2. Sesión de la Comisión de Diputados, 15-9-1924. ADP, u.i. 14.721/2, p. 109. Sesión de la CP, 30-41926. ADP, u.i. 13.151, pp. 35-37.

33 Hemos considerado a los expósitos de las generaciones de la Inclusa de 1906, 1909, 1912, 1915, 1918, 1921 y 1924 , que a la edad reglamentaria ingresaban en el Hospicio.

34 La expósita 5.568/24 a los 14 años salió del Hospicio para ir de criada a casa de un sacerdote y regresó tres años después. Tras una estancia de unos meses se fue definitivamente. Los expósitos 5.207/21 y 5.217/21 que se fueron de voluntarios a los 16 años al Frente Nacional, regresaron tras el final de la Guerra Civil. Uno de ellos salió en 1940 para trabajar en un taller de aviación militar. ADP, u.i. 14.741/2.

35 ADP, u.i. 14.740/2, 14.741/1-2 y 651.

36 Sesión de la CP, 29-5-1925. ADP, u.i. 13.150. 
determinaría su futuro: las chicas, como futuras sirvientas que iban a ser, trabajaban en la cocina, ropero y lavandería, mientras que los varones iban a aprender un oficio a los talleres (Sanchidrián Blanco y Martín Zúñiga 2009: 132).

El nivel de estudios de los expósitos asilados en el Hospicio de Pontevedra no fue muy alto. Solo uno de ellos, de la generación de 1906, llegó a maestro y ejerció como tal. El resto asistía a la escuela del Hospicio y esto era una ventaja frente a los niños gallegos no asilados, de los que solo un 65,6\% acudían asiduamente a la escuela en 1908 (Brey 2005:193). También es verdad que aunque las expósitas salían del Hospicio con pocos estudios, en España, todavía al final de la segunda década del $\mathrm{XX}$, las chicas representaban solo el $26,7 \%$ del total de las personas matriculadas en el bachillerato (Paradas Fernández 2000: 136-149; Amo del Amo 2009: 14).

Ya de adultos, el nivel de estudios de los expósitos de la Inclusa de Pontevedra y los trabajos a los que se dedicaban eran iguales a los de los antiguos asilados en instituciones similares en España, en donde solo una minoría había cursado estudios de Magisterio (Uribe Etxebarría 1996: 264-266; Barba Pérez 2017: 189). Y si la vida laboral de los hospicianos pontevedreses comenzaba pronto, también ocurría lo mismo con los niños no asilados. En el sector pesquero abundaban los menores de 14 años, y en las fábricas de conservas y envases, los niños y niñas de 12 años. La aportación de todos ellos a la economía familiar era importante pero conllevaba el absentismo escolar y un bajo nivel educativo (Muñoz Abeledo 2013: 148).

Sabemos que una parte de los expósitos de la Inclusa de Pontevedra se casaron, porque para ello solicitaron su partida de bautismo a la Institución, y que algunos lo hicieron con personas del mismo pueblo en el que se habían quedado residiendo con su nodriza o con las personas que los habían recogido ${ }^{37}$. Podemos pensar entonces que se habían integrado en la comunidad en la que vivían. Sin embargo, varios expósitos no pudieron salir del bucle de la ilegitimidad, la pobreza y la falta de familia. Una expósita soltera ingresó a su hijo recién nacido en la Inclusa, en 1927, alegando ser pobre y no tener familiares y varios antiguos asilados solicitaron en impreso de pobreza su partida de nacimiento para jubilarse. Otros expósitos fueron procesados por hurto o robo, y a dos que eran matrimonio les retiraron a sus dos hijos, que fueron luego ingresados en la Inclusa, debido a que no podían cuidarlos debidamente por su discapacidad intelectual y su pobreza (ADP, u.i. 962, 975 y 991).

\subsection{Los problemas de identidad y la caren- cia de familia}

La búsqueda por parte de los expósitos de la Inclusa de Pontevedra de su propia identidad y la de su madre no la hemos visto en demasiados casos. No podemos decir si esto es debido a que como la mayoría se quedó con su nodriza tras haber cumplido siete años, la integración en la familia y el pueblo de su ama fue total, o bien a que los propios expósitos sabían que, por haber sido expuestos o depositados en el torno, las probabilidades de reunirse con su madre eran prácticamente nulas si ella no tomaba la iniciativa de recuperarlo.

El deseo de los expósitos de conocer a su progenitora o a sus padres aunque no lo hemos visto expresado muchas veces, sí fue constante a lo largo de los 53 años que tenemos en cuenta. Y todavía sigue presente en los expósitos aún vivos a finales del siglo $\mathrm{XX}$, como podemos ver a través de la prensa ${ }^{38}$.

\subsubsection{Generaciones de 1872-1904}

Algunos expósitos tenían problemas de identidad, no sabían ni su edad exacta ni su apellido y utilizaban el que les habían dado sus vecinos de la aldea en la que habían vivido con su nodriza, que era el de Expósito. Solo se enteraban de sus datos personales al solicitar la partida de nacimiento que necesitaban cuando eran llamados a quintas, o querían casarse o formar parte de las bandas de música militares (Rodríguez Martín 2015: 380-381). El caso más llamativo es el de tres asilados en el Hospicio que antes habían estado en la Inclusa, y que tenían el mismo apellido. De ellos, en 1881, el presidente de la Junta Superior de la Casa Hospicio no podía decir si eran expósitos o no, "(...) por no haberse hallado sus partidas de

37 ADP, u.i. 14.723/1, 14.726/2, 943, 962, 977 y 984

38 "Una mujer reclama a la Diputación de Lleida la identidad de sus padres", El País, (Madrid) 17/4/1998. "Pasado prohibido", El País (Madrid) 17/2/2003. 
bautismo, existiendo tan solo los antecedentes de ser público que dichos acogidos proceden de la Inclusa" 39 . Otro caso de falta de datos es el de un hospiciano de 16 años, José Rey Expósito, que se había presentado voluntario para ser educado como músico en un destacamento militar de Santiago, en 1897. Cuando la Inclusa de Pontevedra remitió la partida de nacimiento que necesitaba el joven, éste pudo ver que no había entrado por el torno sino que era hijo natural, es decir, reconocido por su madre, que la Diputación había autorizado su ingreso al haber muerto ella, y que su verdadero nombre y apellido era F.A. (ADP, u.i. 943). Respecto a la edad, algunos expósitos se enteraban de la verdadera cuando pedían la partida de nacimiento, en algunas ocasiones, para la jubilación. Los años de desfase entre los años reales y los que creían tener eran entre dos y seis (ADP, u.i. 943).

Algunos incluseros, ya de adultos, vivían con la desazón de no conocer su origen. Si las madres no reclamaban a sus hijos para quedárselos, las inclusas no les daban información sobre ellos, no les decían donde se encontraban sus hijos en lactancia externa y, además, no empleaban amas del mismo pueblo donde hubieran sido expuestos (Morales Álvarez 2001: 102). En la Inclusa de Pontevedra hemos encontrado algunos casos de expósitos que deseaban encontrar a su familia, como en 1936, el de uno de 40 años residente en Buenos Aires, “(...) en vista que yo me hallo en una posición desahogada, y con respecto a esto mi orgullo eficaz seria conocer al padre o bien madre, como también podría serles útil" ${ }^{40}$. El administrador de la Inclusa le envió el texto de la nota que la madre del expósito había metido en sus ropas al dejarlo en el torno, pero en el original el nombre del pueblo que iba en el encabezamiento aparecía tachado. El antiguo asilado tenía tanto interés que pidió la aportación de un calígrafo para intentar averiguarlo, pero no tenemos información sobre si la Inclusa accedió a ello y el resultado. Otro expósito, ingresado por el torno en 1895, se lamentaba de la imposibilidad de llegar a conocer a su familia, “(...) siempre esperé de saber quien era mi madre o si existen rastros de mi familia o adonde naci pero el destino no quiso"41. De la Casa de Maternidad y Expósitos de Barcelona hemos encontrado muchas cartas de antiguos asilados en la segunda mitad del siglo XIX que, en su madurez o vejez, preguntaban por sus familiares. Como habían sido depositados en el torno, la respuesta de la Institución era desoladora, pues era que nada se sabía de sus madres y nunca nadie había preguntado por ellos (Rodríguez Martín 2005: 356-357).

\subsubsection{Generaciones de 1904-1925}

Igual que en la etapa anterior, algunos expósitos desconocían la fecha exacta de su nacimiento y también sus apellidos, debido a que a las nodrizas externas no se les daba esta información (ADP, u.i. 962 y 14.728/2), por lo que algunos expósitos utilizaban los del marido de su ama, como explicaba un párroco en 1925,

(...) a L. desde sus primeros años le llamaban Manuel, porque el nombre L. le parecía extravagante y les causaba risa (...) También debo advertirle que, L. firma Manuel C.F., siendo el primer apellido el del marido de la nodriza. Ignorancias y torpezas de la aldea ${ }^{42}$.

Otro expósito, en la década de los veinte, había sido alistado por su ayuntamiento como J. Expósito, y años más tarde se enteró de que tenía dos apellidos, como marcaba la Ley de Registro Civil, y se llamaba M.D.R. (ADP, u.i. 962). Hemos encontrado un caso similar en $1934^{43}$. A veces la confusión con los apellidos era interesada, como sucedió con A. Expósito, alistado como voluntario por su ayuntamiento, del que no había inscripción en el archivo de su parroquia. La razón que daba el párroco, en 1940, era que su antecesor le había cambiado el nombre para librarlo del servicio militar, y no era la primera vez que hacía esto, “(...) mi antecesor R.C. se lo hizo a varios, tanto a parroquianos como a incluseros (...) y así libró a muchos del servicio militar"44. El cambio de apellidos

\footnotetext{
Sesión de la Comisión Asociada, 17-11-1881. ADP, u.i. 13.024, pp. 104-105.

Escrito del expósito 1.666/96 al administrador de la Inclusa de Pontevedra, 27-1-1936. ADP, u.i. 943.

Carta de un expósito a la Hermana Superiora de la Inclusa de Pontevedra, 25-9-1950. ADP, u.i. 943.

42 Escrito del párroco de Vilar de Ortelle, 1925. ADP, u.i. 962.

43 El inclusero A. Expósito, en 1934, al solicitar su certificado de nacimiento se enteró que ese no era su apellido, sino que tenía dos muy comunes en Galicia. ADP, u.i. 962.

44 Carta del presbítero de Villar de Ortelle, 31-7-1940. ADP, u.i. 962.
} 
intencionado agravaba los problemas de identidad de los expósitos cuando eran adultos, como le ocurrió a una antigua asilada de 20 años, según explicaba el secretario de la Inclusa,

Revisé lo tomos correspondientes a los años 1907 a 1914 y no hallé ingresada en esta Inclusa la niña I.R. (...) Estos casos se dan con muchísima frecuencia por esto no me llama la atención el que sea uno más, en que los interesados en tener una expósita se valen de documentos de otras personas para poder conseguirla y le cambian después el nombre para así despistar a los familiares de la niña ${ }^{45}$.

A veces, el traspaso no oficial de un expósito entre nodrizas traía consecuencias cuando el niño se hacía adulto, como afirmaba un párroco en 1940,

Era costumbre en esas gentes pagar el viaje y dar una pequeña gratificación a una nodriza que practicara la lactancia natural para que esta se hiciese cargo de un expósito, pero al llegar a esa hacían entrega de él a la que le había pagado, por lo que resultaba que oficialmente se hallaba en poder de la que lo llevó de esta Inclusa, pero en realidad lo criaba otra (...) pero aun hay mas, a muchos les cambiaban el nombre y en algunos casos fueron declarados prófugos debido a que, por haberle muerto la nodriza ignoraban su verdadero nombre y los daban por desconocidos ${ }^{46}$.

Varios expósitos adultos intentaron encontrar a su familia, quizás buscando su verdadera identidad o una estabilidad que no habían tenido de pequeños. Pensemos que algunos debían haber sufrido al ser devueltos a los 7 años por su nodriza e ingresar en el Hospicio. Otros, además, habían pasado tres o cuatro veces por el cambio de amas de lactancia o de destete (ADP, u.i. 14.725/3-14.730/3). Ya en el Hospicio, algunos expósitos habían sido prohijados o recogidos por algún matrimonio, y no siempre la convivencia había sido posible, por lo que habían sido devueltos y de nuevo habían ingresado en la Institución ${ }^{47}$. El médico Tolosa Latour, en 1916, creía que los jóvenes expósitos al salir de los hospicios, aunque lo hacían con un oficio aprendido y muchos encontraban trabajo, se sentían desamparados, "(...) muchos de ellos se sienten tan abandonados como al nacer" (Tolosa Latour 1916: 20). Quizás por esa razón en las solicitudes de información a la Inclusa de Pontevedra, los expósitos dejaban claro el deseo de saber de su familia. Un joven se enteró de que una mujer había ido a preguntar por él a la aldea donde había vivido con su nodriza, y sospechaba que pudiera ser su madre, por lo que pedía más detalles al Administrador,

Hace aproximadamente un año que recibí una carta de mi madre adoptiva (la nodriza) (...) en cuya carta me decía que por indicación de esa Casa de Espósitos, había ido una señora á saber de mí, y, que creían seria mi verdadera madre por el mucho interés que demostró (...) y como hasta la fecha no he tenido ninguna otra noticia al respecto, por eso es, Señor, que me permito dirigirme á $\mathrm{Vd}^{48}$.

En otras solicitudes se ve también la soledad en la que vivían algunos expósitos, como una joven, en 1935, tras haber fallecido su nodriza y haberse ido el viudo a vivir con una mujer a otro municipio. Un maestro que conocía a la muchacha trasladó a la Inclusa su deseo de conocer a sus padres,

(...) quedando la pobre chica sola, en ese lugar donde solo hay dos casas. En tales circunstancias vino junto de mi por no haber aquí párroco actualmente, a fin de que yo hiciese gestiones para saberle quienes eran sus padres o parientes, pues ella ya una joven de 18 años deseaba conocerlos ${ }^{49}$.

En la mayoría de las ocasiones la Inclusa no podía ofrecer información alguna. A la petición

45 Carta del secretario-contador de la Inclusa al Registro Civil de Vigo, 20-6-1934. ADP, u.i. 962.

46 Carta a la Inclusa, 19-4-1940. ADP, u.i. 962.

47 Uno de estos casos es el de la expósita 5.140/21 que, en sus primeros diez años de vida, experimentó los siguientes cambios: primero vivió con una nodriza, luego ingresó en el Hospicio, de donde fue recogida por un matrimonio con el que convivió durante siete meses tras los cuales volvió a entrar en el Hospicio. Fue recogida entonces por una mujer que poco después la devolvió a la Institución, de donde volvió a salir, ya de forma definitiva, con unos consortes. Otra expósita, la 5.177/21, en sus primeros siete años de vida tuvo tres nodrizas, después entró en el Hospicio, de donde fue recogida por una mujer que al cabo de unos meses la devolvió, por lo que reingresó en la Institución. ADP, u.i. 944, 14.729/3 y 17.741/2.

48 Escrito del expósito 2.584/05 al Administrador de la Inclusa, 20-4-1927. ADP, u.i. 962.

49 Carta de la expósita 4.608/17 a la Inclusa, 24-6-1935. ADP, u.i. 962. 
de un asilado ingresado en 1915, "Se lo ruego Encarecida mente que se informe haber si apareze mi familia quesería para mi la felicidad mas grande al saber de mi padres" ${ }^{50}$, no había respuesta posible, pues el interesado había sido dejado en el torno con una nota anónima en la que solo se pedía nombre y apellidos (ADP, u.i. 14.728/2). Frente a una situación de este tipo, en 1930, una expósita de 23 años con muchas ganas de conocer a su familia, recurrió a la prensa,

Una convecina nuestra esposa de un funcionario público que es buen amigo, se nos acercó con la pretensión muy humana y digna de alabarse, de que en las columnas de El Progreso (...) nos refiriéramos a su origen con el muy plausible fin de ver si con ello logra saber quienes son sus padres (...) sin afán de lucro alguno y sí llevada del amor filial ${ }^{51}$.

Y para lograr sus propósitos proporcionó todos los datos referidos a su ingreso en la Inclusa, incluidos el texto de la nota y la descripción de la medalla con la que había sido abandonada, y su dirección particular.

La falta de familia de los expósitos se hacía manifiesta cuando el Ejército, sobre todo a raíz de los acontecimientos de 1934 en Asturias y de la Guerra civil, comunicaba el fallecimiento de alguno de ellos, porque lo hacía a la Inclusa (ADP, u.i. 14.721/1). También la podemos ver en la carta de un joven soldado, en la Guerra civil, en la que se lamentaba de que su nodriza no le contestaba a sus misivas, y en el destinatario de su queja: el administrador de la Inclusa a la que había pertenecido de niño (ADP, u.i. 984).

\section{La consideración social de los expósitos en España}

Los expósitos debían enfrentarse en su vida adulta a la mala consideración que una parte de la sociedad tenía de ellos. En la segunda mitad del siglo XIX e, incluso, en las dos primeras décadas del XX, en la prensa se reflejaba la idea, muy extendida, de que eran hijos de padres adúlteros o inmorales, "(...) de un capricho o de una pasión culpable" (Mijares del Real 1872: 99), “(...) criaturas que la depravación y la infamia arrojan a esos santos asilos" ${ }^{52}$. Otras veces se declaraba que el hecho de haber sido echados al torno demostraba que eran hijos de padres egoístas y sin sentimientos, “(...) de un padre sin corazón y una madre sin entrañas" 53 . Solo en algún caso también se citaba la pobreza como causa del abandono, “(...) infortunadas criaturas, que desde el momento de nacer son abandonadas por sus padres, ya por vergüenza de su crimen, ya obligados por la pobreza" 54 . En una encuesta realizada por el Ateneo de Madrid, en los años 1901 y 1902, algunas de las respuestas dadas en Galicia sobre la consideración de los hijos ilegítimos eran negativas, "son mal mirados" o "Generalmente van a parar a la Casa de expósitos" (González Reboredo 1990: 68-69). Estas opiniones entran en contradicción con la idea, sostenida por Pardo Bazán y Fernández Flórez, de que en el campo gallego había permisividad y que los hijos ilegítimos se los quedaban las madres y no los echaban a las inclusas (Freire Lestón 1993: 23).

La mala consideración de los expósitos llegaba a los políticos. Uno de ellos, Ramón Albó $^{55}$, en 1903, afirmaba que los expósitos eran hijos del vicio y portadores de enfermedades, “(...) muchos niños cuando ingresan en la Casa (Inclusa) están muriéndose, o por el abandono (...) o por la exposición o por terribles y repugnantes enfermedades hereditarias que confirman su vicioso origen" (Albó Martí 1903: s.p.). Algunos responsables de las inclusas no tenían mejor opinión. En 1903, el secretario de la Casa de Maternidad y Expósitos de Barcelona opinaba que los niños asilados eran unas víctimas debido a sus padres, “(...) víctimas del vicio o de la desgracia de quienes les dieron el ser" ${ }^{\prime \prime}$. Los médicos de la Inclusa de Valladolid, en 1920, para explicar la alta mortalidad aseguraban que

\footnotetext{
Carta del expósito 4.346/15 al Administrador de la Inclusa, 20-1-1945. ADP, u.i. 962.

"Quiere saber quien son sus padres", El Progreso (Pontevedra) 22/4/1930, http://biblioteca.galiciana.gal.

52 "Beneficencia provincial de Orense", El Heraldo gallego (Ourense) 15/2/1879, pp. 49-50, http://biblioteca.galiciana.gal.

53 "La Hermana de la Caridad", El Obrero (Pontevedra) 7/3/1898.

54 "Beneficencia provincial de Orense", El Heraldo gallego (Ourense) 5/9/1879, pp. 338-339, http://biblioteca.galiciana.gal.

55 Ramón Albó Martí fue concejal del Ayuntamiento de Barcelona, diputado a Cortes y presidente del Tribunal Tutelar de Menores. Gran Enciclopedia Catalana 1986: 390, vol. I.

56 "Fiesta simpática", El Noticiero Universal (Barcelona), 22/11/1903.
} 
a estos establecimientos llegaban las piltrafas humanas con taras patológicas (Barba Pérez 2017: 653-654), y la propia Junta Directiva de la Casa de Expósitos de Vizcaya advertía, en 1925, sobre los peligros de la convivencia de la población con los expósitos que vivían en las casas y los pueblos de sus nodrizas,

(...) hemos de subrayar la existencia de un grave problema (...) Se trata de la invasión del elemento expósito en la población rural, que se produce en la proporción de más de 100 individuos cada año (...) Física y moralmente lleva la generalidad de los expósitos predisposiciones, perniciosas siempre, pero más aún si han de manifestarse y desarrollarse en un ambiente que de otro modo, por sus condiciones de vida se vería libre de estos peligros. (Memoria 1925: 7)

En la novela Cañas y barro, publicada en 1902, se refleja la situación y la desconsideración social hacia los expósitos. Uno de los personajes es una niña, tímida y arisca, que había sido sacada de una inclusa a los seis años por una familia, compartía su miseria, trabajaba duramente y cargaba con su condición de expósita, "Se llamaba Visanteta, pero todos, para que no olvidase su origen, con esa crueldad inconsciente de la incultura popular, le llamaron la Borda" (Blasco Ibáñez 2009: 54). En La hija del mar, de Rosalía de Castro, los expósitos son presentados como seres tristes y desarraigados a los que, debido a su mal origen, era necesario ayudar,

(...) a vosotras, las de tiernos sentimientos y alma compasiva, es a quienes suplico que tendáis la mano a esos desamparados seres que vagan sobre la tierra, como frías y solitarias sombras, como hojas que arrastran los vientos encontrados. Tendámosles la mano todas las mujeres (...) ¿No son ellos el fruto de nuestra debilidad o de nuestro crimen? (Castro 1945: 103)

En la prensa pontevedresa del período que analizamos, 1872-1925, las noticias sobre los expósitos de la Inclusa de Pontevedra no son muy numerosas, a pesar de que en esos 53 años ingresaron 5.702 niños (ADP, u.i. 14.721/214.730/3). Creemos que socialmente desagradaba ver recién nacidos expuestos en las calles o caminos, pero si se depositaban en el torno y luego estaban a cargo de una inclusa, caían en el olvido, a pesar de ser un contingente importante. El número entradas anuales de niños en las inclusas españolas, entre 1859 y 1864, estuvo alrededor de los dieciocho mil y no hubo un descenso demasiado grande en los dos primeros decenios del siglo XX, puesto que ingresaron una media de 15.000 menores anualmente (Junta General de Estadística 1866: 178; Pérez Moreda 2005: 117-118).

Las pocas noticias que en la prensa de Pontevedra aparecían sobre los expósitos eran, mayoritariamente, negativas, pues se les presentaba como autores de hurtos, robos y fugas de la cárcel, o como carteristas y timadores ${ }^{57}$. De todos ellos, y también del que pegó dos tiros en una reyerta y del autor confeso de la muerte de un hombre, se especificaba su origen, "El criminal procede de la Inclusa de esta capital" 58 . Nada más hemos visto un artículo que explicaba, y en parte justificaba, la acción criminal de un expósito basándose en la falta de amor maternal,

Nos asustamos con sus crímenes, pero nadie se detiene á estudiar si esos crímenes son el fruto de esa educación que han recibido por manos extrañas, siempre pesadas, duras, crueles, para el huérfano, para el inclusero, para ese ser desventurado, arrojado como estorbo en el torno de una Inclusa, sin las caricias ni el amor de una madre ${ }^{59}$.

La Inclusa de Pontevedra también era poco nombrada en la prensa, tanto en el siglo XIX (Rodríguez Martín 2008: 380) como en el XX, en las tres primeras décadas. Por ejemplo, en $E l$ Progreso, en 1917, aparece 28 veces citada, pero en 24 de ellas en la sección de defunciones, y las cuatro restantes por cuestiones administrativas, como el aviso de pago a las nodrizas o acuerdos de la Comisión Provincial autorizando el ingreso de algún niño ${ }^{60}$. En otros periódicos,

57 “Crónica provincial”, La Correspondencia gallega (Pontevedra) 15/3/1907, http://biblioteca.galiciana.gal. "De la Provincia", "De Galicia", "Centros", "Comisión Provincial" y "Noticias", El Progreso, (Pontevedra) 27/3/1912, 26/6/1912, 10/7/1913, 6/12/1926 y 1/5/1927, respectivamente, http://biblioteca.galiciana.gal.

58 "El crimen de Geve" y "Sección de noticias", La Correspondencia gallega (Pontevedra) 22/7/1908 y 4/7/1914, respectivamente, http://biblioteca.galiciana.gal.

59 "Reos de muerte", La Correspondencia gallega (Pontevedra) 5/4/1905, http://biblioteca.galiciana.gal.

60 "Noticias" y “Cultos", El Progreso (Pontevedra) 14/9/1918 y 27/12/1912, respectivamente, http://biblioteca.galiciana.gal. 
las pocas noticias sobre la Inclusa se referían a la magnanimidad de la Diputación por las comidas o cenas extraordinarias que ofrecía a las nodrizas internas y los asilados para celebrar el matrimonio del Rey o la Nochebuena ${ }^{61}$, o por la compra de una estufa de desinfección, "Plácemes entusiastas merecen el muy digno y celoso Presidente Sr. Casas, la muy laboriosa y activa Superiora Sor Rafael Echarle y la Junta que ayuda con su cooperación a tan prestigiosos funcionarios" ${ }^{2}$. No hemos encontrado en la prensa pontevedresa consultada denuncias 0 debates respecto a la mortalidad en la Inclusa y sus causas, o a las condiciones de los edificios en los que se ubicó la Institución. Creemos que el motivo era el rechazo generalizado hacia los expósitos, que provocaba que se hablara poco de ellos. Sin embargo, en la tercera y cuarta décadas del siglo XX, empezó a cambiar algo la percepción social sobre estos niños. Un periódico de Pontevedra dio una noticia positiva sobre un antiguo asilado de la Inclusa de A Coruña, pues había llegado a ser médico, “(...) sin otro apoyo que el de su propio esfuerzo e inteligencia" ${ }^{\prime 3}$. Otro diario señaló que el protagonista de la película Currito de la Cruz era un inclusero que triunfaba como torero ${ }^{64}$. No obstante, el ser expósito era una dificultad en la vida de una persona, como afirmaba un periódico pontevedrés, "El hijo ilegitimo (...) si sobrevive al matadero de la Inclusa, arrastra toda la vida un estigma infamante, que agravarán y ahondarán la pobreza de espíritu de las gentes, los prejuicios sociales y la estrechez espiritual" 65 . Para eliminar el estigma de expósito ya vimos que en 1903 se había establecido la imposición de dos apellidos. Posteriormente, algunas inclusas cambiaron de nombre, entre ellas la de Pontevedra, que en la década de los cuarenta, pasó a llamarse Casa Cuna, y la de Madrid, que en 1927 se convirtió en el Instituto Provincial de Puericultura (Fariña Jamardo y Pereira Figueroa 1986: 370; Revuelta Eugercios 2011: 221).

Actualmente, llevar el apellido Expósito le resulta a algunas personas una carga y por esta razón varios bufetes jurídicos ofrecen, entre sus servicios, gestionar el cambio de apellido, dado que está legalmente contemplado que se pueda sustituir el de Expósito o cualquier otro que denote un origen desconocido por uno de uso común

\section{Conclusiones}

Podemos concluir que bastantes expósitos de la Inclusa de Pontevedra vivieron en la pobreza lo largo de su vida. Ya al nacer, la reflejaban el estado y la escasez de las ropas que llevaban, y las notas con las que habían sido abandonados, mal redactadas y llenas de faltas de ortografía. Luego, cuando empezaban su vida adulta, la inmensa mayoría lo hacía sin bienes, aunque algunos de los que se habían quedado con sus nodrizas después de haber cumplido los siete años heredaban alguna finca, la casa o una parte de ella. Otros, sin embargo, no recibían compensación alguna a pesar de haber trabajado desde edades muy tempranas sin salario alguno. Los que sí tenían algo de dinero ahorrado eran los que habían ingresado en el Hospicio y habían trabajado en talleres de la capital. Las normas de la Diputación de 1925 estableciendo el pago anual de una cantidad de dinero a los que tuvieran jóvenes expósitos trabajando supusieron una mejora, pero las generaciones anteriores de asilados ya no pudieron beneficiarse de ellas. Las chicas lo tenían peor al salir del Hospicio, pues lo hacían sin ahorros y con la perspectiva de trabajar como sirvientas, mayoritariamente. Los trabajos duros y mal remunerados eran otra característica de los expósitos, así como su bajo nivel de estudios. Cuando llegaban a la vejez, algunos seguían viviendo en la pobreza e, incluso, acababan sus días en una institución benéfica. Había expósitos que, además, tenían problemas de identidad, dado que hasta que no pedían su partida de nacimiento desconocían los apellidos que les había impuesto el Registro Civil y no sabían su edad exacta.

Aunque muchos expósitos se integraron en la familia de sus nodrizas e, incluso, lograron casarse, para algunos no conocer a su madre y familia biológica era un motivo de pesar, por lo que intentaron buscarla, aunque con poco éxito al haber sido dejados en el torno o haber sido expuestos.

\footnotetext{
${ }^{61}$ “Comisión provincial”, La Correspondencia gallega (Pontevedra) 8/5/1909 y 20/12/1909, http://biblioteca.galiciana.gal. "Hospicianos”, El Progreso (Pontevedra) 9/12/1918.

62 "Estufa de desinfección", La Correspondencia gallega (Pontevedra) 10/9/1909, http://biblioteca.galiciana.gal.

63 "Noticias", El Progreso (Pontevedra) 12/7/1931, http://biblioteca.galiciana.gal.

64 "Cinematografía", El Diario de Pontevedra (Pontevedra) 6/2/1926, http://biblioteca.galiciana.gal.

65 “La legitimidad de los niños", El Diario de Pontevedra (Pontevedra) 16/7/1924, http://biblioteca.galiciana.gal.
} 
La consideración social que tenían los expósitos era muy baja porque, según alguna prensa, eran hijos de relaciones ilícitas o del vicio, y habían heredado enfermedades vergonzosas. Esta misma opinión la tenían también algunos responsables de las inclusas que llegaban a considerarlos un peligro para las poblaciones en las que residían con sus nodrizas. Los expósitos estaban, entonces, en el nivel más bajo entre los pobres por no tener bienes y, además, ser hijos de padres desconocidos y carecer de familia y consideración social. En Pontevedra, estas circunstancias se reflejaban en el desinterés hacia ellos. A pesar de ser un grupo importante de la población, tenían un mínimo protagonismo en la prensa local. Cuando a principios del siglo XX empezó a cambiar lentamente la visión de la sociedad y los poderes públicos sobre los expósitos, el objetivo no fue aceptar su condición de hijos de padres desconocidos sino disimularla, y para ello se les impusieron dos apellidos y se cambió el nombre a las instituciones que los albergaban.

\section{Referencias bibliográficas}

Abella Blave, Fermín (1903): Manual del Registro Civil. Madrid: Imprenta de El Consultor.

Acosta Sánchez, José Antonio (1995): Beneficencia, formación y empleo en Valencia (1874-1902). Valencia: Universidad de Valencia.

Albó Martí, Ramón (1903): "Bodas de oro de la Casa Provincial de Maternidad y Expósitos", La Hormiga de oro (Barcelona) 28/11/1903.

Amo del Amo, Ma Cruz del (2009): "La educación de las mujeres en España: de la amiga a la Universidad", Participación educativa 11, pp. 8-22, www.mecd.gob.es/revista-cee/pdf/n11-amo-amo.pdf.

Arenal, Concepción (1878): “El torno", La Voz de la Caridad 198, pp. 91-94.

Ballesteros Doncel, Esmeralda (1999): "El coste de la vida en España (1800-1890). Diferencias entre el salario monetario y el presupuesto familiar", en M. González Portilla y K. Zarraga Sangroniz (eds.), Actas del IV Congreso de la Asociación de Demografía Histórica. Bilbao: Universidad del País Vasco, pp. 573-586.

Barba Pérez, Ma Ángeles (2017): La alimentación y cuidados en los lactantes en el Hospicio provincial de Valladolid. Tesis doctoral. Valladolid: Universidad de Valladolid, http://uvadoc.uva.es/ handle/10324/27671.

Bardet, Jean-Pierre (1991): "La société et l'abandon", en Enfance abandonnée et société en Europe, XIVXX siècle. Roma: École Française de Roma, pp. 3-26.

Benso, Carmen y Rosa María Cid Galante (2011): "As conquistas femininas na Galicia do primeiro terzo do século XX”, en J. de Juana López y J. Prada Rodríguez (dirs.), As mulleres en Galicia no século XX. Vigo: Indo Edicións, pp. 48-50.

Blanco Herrero, Miguel (1869): De la beneficencia pública en España. Madrid: Imprenta de J.M. Pérez.

Blasco Ibáñez, Vicente (2009): Cañas y barro. Madrid: Alianza.

Borrás Llop, José María (1996): “Zagales, pinches, gamenes... aproximaciones al trabajo infantil”, en J. M. Borrás LLop (dir.), Historia de la infancia en la España contemporánea: 1834-1936. Madrid: Ministerio de Trabajo y Asuntos Sociales, pp. 229-346.

Brey, Gérard (2005): "La sociedad gallega", en J. de Juana y J. Prada (coords.), Historia contemporánea de Galicia. Barcelona: Ariel, pp. 169-202.

Capel Martínez, Rosa María (1982): "La apertura del horizonte cultural femenino: Fernández de Castro y los Congresos Pedagógicos del siglo XIX”, en Mujer y sociedad en España (1700-1975). Madrid: Ministerio de Cultura, pp. 109-145.

Castro, Rosalía de (1945): La hija del mar. Buenos Aires: Ediciones Universal.

Castro, Xavier (2007): Historia da vida cotiá en Galicia: séculos XIX e XX. Vigo: Nigratea.

(2008): "Historia da infancia na Galicia contemporánea", Minius 16, pp. 63-100.

Codina Langlín, Ramón (1892): El Congreso Internacional de Beneficencia Pública de 1889 en París: la organización general de la beneficencia pública en Francia. Barcelona: Tipografía de la Casa Provincial de Caridad.

Consejo Superior de Protección a la Infancia (1908): Leyes y disposiciones vigentes de Protección a la Infancia. Madrid: Imprenta del Asilo de Huérfanos.

Díez, Asunción (1992): "El abandono de niños en la Asturias rural del siglo XIX. Avance sobre una investigación", Boletín del Real Instituto de Estudios Asturianos 140, pp. 453- 471.

Diputación Provincial (1883): Reglamento para el régimen interior del Hospicio Provincial de Zaragoza en sus diferentes departamentos. Zaragoza: Imprenta del Hospicio provincial. 
Diputación Provincial de Guipúzcoa (1916): Reglamento general de expósitos para la provincia de Guipúzcoa. San Sebastián: Imprenta de la Provincia, http://atzoatzokoa.gipuzkoakultura.net/c3f15/index.php.

Espina Pérez, Pedro (2005): Historia de la Inclusa de Madrid: vista a través de los artículos y trabajos históricos, recopilación de textos y notas, años 1400-2000. Madrid: Defensor del Menor, www.cervantesvirtual.com/...inclusa-de-madrid.../0112f22a-82b2-11df-acc7-002185ce6.

Fariña Jamardo, Xosé y Miguel Pereira Figueroa (1986): A Deputación de Pontevedra. Pontevedra: Diputación Provincial.

Fonte, Teodoro Afonso da (2005): No limiar da honra e da pobreza: a infancia desvalida e abandonada no Alto Minho (1698-1924). Vila Praia de Âncora: Ancorensis Cooperativa de Ensino.

Freire Lestón, Xosé Vicenzo (1993): Lembranzas dun mundo esquecido: muller, política e sociedade na Galicia contemporánea 1900-1939. Santiago de Compostela: Laiovento.

González Reboredo, Xosé Manuel (supervisor) (1990): Nacemento, casamento e morte en Galicia: respostas á enquisa do Ateneo de Madrid: 1901-1902. Santiago de Compostela: Consello da Cultura Galega.

Juderías, Julián (1912): La infancia abandonada. Madrid: Tipografía de Jaime Ratés.

Junta General de Estadística (1866): Anuario estadístico de España, 1862-1865. Madrid: Imprenta Nacional.

Langellotti, Alessandra y Carlo M. Travaglini (1991): "L'infanzia abbandonata nel Viterbese (sec. XVIIIXX)”, en Enfance abandonnée et société en Europe, XIV-XX siècle. Roma: École Française de Roma, pp. 741-784.

Lopes, $\mathrm{M}^{\mathrm{a}}$ Antónia (2004): Crianças e jovens em risco nos séculos XVIII e XIX: o caso português no contexto europeu. Coimbra: Almedina.

López Keller, Estrella (1990): "Hacia la quiebra de la mentalidad liberal: las resistencias al cambio", en Historia de la acción social pública en España. Beneficencia y previsión. Madrid: Ministerio de Trabajo y Seguridad Social.

Memoria de la Casa-Cuna y Casa de Maternidad de Guipúzcoa (1925): Memoria de la Casa de Expósitos de Vizcaya. Bilbao: Imprenta de la Junta de Protección a la Infancia.

Mijares del Real, Emilia (1874): "Las nodrizas", La Voz de la Caridad 94, pp. 347-351.

Montiel i Pastor, Josep (2004): “De la creació fins a la Mancomunitat, 1853-1914”, en La Casa de Maternitat $i$ Expòsits. Les Corts. Barcelona: Ayuntamiento / Diputación Provincial de Barcelona, pp. 27-75.

Morales Álvarez, Ángel (2001): Casa Cuna de Ponferrada, 1775-1937. Ponferrada: Instituto de Estudios Bercianos.

Muñoz Abeledo, Luisa (2013): “El trabajo infantil en las industrias pesqueras de España, 1850-1936”, en J. M. Borrás LLop (ed.), El trabajo infantil en España (1700-1950). Barcelona: Icaria.

Paradas Fernández, Mercedes (2000): "La incorporación de la mujer al sistema educativo en España y Andalucía (siglo XX)", en E. Barranquero Texeira y L. Prieto Borrego (coords.), Mujeres en la contemporaneidad: Educación, cultura, imagen. Málaga: Universidad de Málaga, pp. 136-149.

Pérez Moreda, Vicente (2005): La infancia abandonada en España. Madrid: Real Academia de la Historia.

Ramas Varo, María Luisa (2001): La protección legal de la infancia en España. Orígenes y aplicación en Madrid (1900-1914). Madrid, Consejo Económico y Social.

Revuelta Eugercios, Bárbara (2011): Los usos de la inclusa de Madrid, mortalidad y retorno a principios del siglo XX. Tesis doctoral. Madrid: Universidad Complutense, https://eprints.ucm.es/13772/1/ T33310.pdf.

Rodríguez Martín, Ana María (2001): “Algúns aspectos relativos á Inclusa de Pontevedra (1872-1903)", Pontevedra. Revista de estudios provinciais 16, pp. 73-84.

(2003): "La Inclusa de Pontevedra, 1872-1903", Pontevedra. Revista de estudios provinciais 19, pp. 179-204.

(2005): Las mujeres y la beneficencia en la segunda mitad del siglo XIX. La Casa de Maternidady Expósitos de Barcelona, 1853-1903. Tesis doctoral inédita. Barcelona: Universidad de Barcelona.

- (2008): "El destino de los niños de la Inclusa de Pontevedra, 1872-1903", Cuadernos de Estudios Gallegos 121, pp. 353-388, http://estudiosgallegos.revistas.csic.es/index.php/estudiosgallegos/article/ view/48/48.

(2015): “El Hospicio de Pontevedra, 1853-1903”, Pontevedra. Revista de estudos 24, pp. 123-191.

Román Portas, Luz (1989): La asistencia social en Galicia: el Hospicio de Pobres de Santiago de Compostela (1860-1900). A Coruña: Diputación Provincial.

Roure, Conrado (1878): Los expósitos. Barcelona: Imprenta Doménech. 
Salas Auséns, José Antonio (2006): "Del abandono a la inserción social: los expósitos del Hospital de Nuestra Señora de Gracia de Zaragoza en los siglos XVIII-XIX”, en J. A. Salas Auséns (ed.), Migraciones y movilidad social en el Valle del Ebro (siglos XVI-XVIII). Bilbao: Universidad del País Vasco, pp. 163-185.

San Martín, Alejandro (1985): “Trabajo de las mujeres”, en Reformas sociales. Información oral y escrita. 1889-1893. Madrid: Ministerio de Trabajo y Seguridad Social, vol. 2, pp. 149-169.

Sánchez Fernández, Luis Vicente; Juan Carlos Cobo Barquín y Radhamés Hernández (2013): “marginación y pobreza desde la cuna: el niño expósito en el Concejo de Siero, Asturias (1800-1936)", Revista de Demografía Histórica 31/2, pp. 131-165, https://dialnet.unirioja.es/servlet/articulo?codigo=5160943.

Sanchidrián Blanco, Carmen y Martín Zúñiga, Francisco (2009): "Protección y reeducación de la infancia abandonada: la Casa de la Misericordia de Málaga (1862-1936)”, Bordón. Revista de pedagogía, 61/4, pp. 123-140, https://recyt.fecyt.es/index.php/BORDON/article/view/28818/15373.

Seijo Castro, Lois (2015): A resposta institucional á pobreza. Lugo (1875-1905). Tesis doctoral. Santiago de Compostela: Universidad de Santiago de Compostela, https://www.tdx.cat/handle/10347/14750.

Serrano Ruiz-Calderón, Manuel (2003): "El abandono de menores: su regulación en el ámbito penal", Revista del Ministerio de Trabajo y Asuntos Sociales 45, pp. 38-41, https://dialnet.unirioja.es/servlet/ articulo? codigo $=747095$.

Soto Carmona, Álvaro (1989): El trabajo industrial en la España contemporánea (1874-1936). Barcelona: Anthropos.

Tolosa Latour, Manuel (1916): La defensa del niño en España. Madrid: Imprenta del Asilo de Huérfanos.

Uribe Etxebarría, Arantzazu (1996): Marginalidad protegida: mujeres y niños abandonados en Navarra 1890-1930. Bilbao: Universidad del País Vasco.

Valverde Lamsfus, Lola (1994): Entre el deshonor y la miseria. Infancia abandonada en Guipúzcoa y Navarra. Siglos XVIII y XIX. Bilbao: Universidad del País Vasco. 
